\title{
Noise pollution and its effects on medical care workers and patients in hospitals
}

\author{
${ }^{1 *}$ D. F. Juang; ${ }^{1}$ C. H. Lee; ${ }^{1}$ T. Yang; ${ }^{2}$ M. C. Chang \\ ${ }^{1}$ Department of Health Business Administration, Meiho University, 24F, 230, Ming-Chuan Second Road, Kaohsiung \\ 806, Taiwan \\ ${ }^{2}$ Longcyuan Veterans Hospital, Neipu, Pingtung County 912, Taiwan
}

Received 24 May 2010; revised 17 June 2010; accepted 25 July 2010; available online 1 September 2010

\begin{abstract}
The objectives of this study are to investigate the levels of noise pollution in some hospitals in Taiwan and to study the effects of noise pollution on the physiological and psychological reactions and annoyance response of medical care staff, patients and visitors in these hospitals. An instrument for the measurement of sound level was used and a self-answered survey questionnaire on noise pollution was administered. Results showed that the daily average sound levels measured inside these hospitals during daytime were between 52.6 and 64.6 decibels. These are higher than the current daytime environmental noise limit of 50 decibels in Taiwan. Most nursing staff members expressed that "talking of visitors or patient's family members" is the major source of noise inside the wards, whereas "talking of visitors or patient's family members" and "children playing" are the two major noise sources outside the wards. However, most patients or visitors claimed that "doors opening or closing" and "patients moaning or crying" are the two major sources of noise inside the wards. "Footsteps," "renovation of hospitals," "talking of visitors or patient's family members," "shouting of nursing staff” and "doors opening or closing” are the five major noise sources outside the wards. To conclude, noise pollution inside and outside the wards either directly or indirectly affects, in a simultaneous manner, the subjective perception of noise, emotions, physiology and experience of noise inside and outside the wards of both the medical care staff and the patients and visitors.
\end{abstract}

Keywords: Ambient noise; Annoyance response; Sound levels; Subjective perception

\section{INTRODUCTION}

The health effects of noise pollution have been studied by many researchers in recent years. Some researchers studied the impact of environmental noise on exposed population (Ising and Kruppa, 2004; Piccolo et al., 2005; Tang and Wang, 2007; Banerjee, 2008; Banerjee, et al., 2009; Monazzam and Nassiri, 2009; Omidvari and Nouri, 2009), while some others investigated the risk of workers exposed to noise pollution in different working places (Nassiri and Golbabai, 1993; Giardino and Durkt, 1996; Morrison et al., 2003; Yildirim et al., 2007; Roozbahani et al., 2009).

Many studies have revealed that extended exposure to noise pollution may cause auditory and nonauditory disorders, such as temporary or permanent hearing loss (Selfe, 1982; Willett, 1991; Nassiri and Golbabai, 1993; Yildirim et al., 2007; Keipert, 2008), sleep disruption (Freedman et al., 1999; Freedman et

《*Corresponding Author Email: x00002060@email.meiho.edu.tw Tel.: +886 8779 9821; Fax: +886 87780673 al., 2001), vertigo, agitation, weariness, hypertension, gastrointestinal system problems (including gastric and duodenal ulcer), cardiac arrhythmia, nervous and psychic disorders (Nicholas et al., 1993; Buemi et al.,1995; Job, 1996; Holmberg and Coon, 1999; Van Kempen et al., 2002; Ising and Kruppa, 2004; Penney and Earl, 2004; Roozbahani et al., 2009) and so on. Therefore, it is very important that medicare givers should provide a quite environment for the patients since unwanted sound could have a negative impact on patient outcomes. However, Meyer-Falcke et al. (1994) depicted that the maximum sound level of the technical equipment was even surpassed by avoidable background noise caused by the staff in the surgical intensive care unit and the anaesthetic and recovery room. They also concluded that sound level was low in dangerous situations and high during routine work. Allaouchiche et al. (2002) found staff conversation caused $56 \%$ of sounds greater than $65 \mathrm{~dB}$ and other 
noise sources (alarm, telephone, nursing care) were each less than $10 \%$ of these sounds. Ulrich and Zimring (2004) indicated that many studies have reported high noise levels in most hospitals in USA. They reviewed these articles and summarized two general sources of noise in hospitals. First one is the noises from paging systems, alarms, bedrails, telephones, staff voices, ice machines, pneumatic tubes, carts and roommates. Second one includes the surfaces of the floors, walls and ceilings hospitals which usually are hard and reflect sound rather than absorb it. Cmiel et al. (2004) reported noise is a primary cause of sleep deprivation and disturbance among patients and it increases their anxiety and decreases their confidence in the clinical competence of the staff. They believed prolonged exposure to environmental noise can increase anxiety and stress, ultimately impacting patient safety. Blomkvist et al. (2005) also studied the effects of noise pollution on the patients in a coronary critical care unit and found that the patients judged healthcare worker attitudes and care to be much better during the lower acoustical periods. Therefore, it is very important to keep the noise levels down in medical institutions.

Medicare givers should provide a quite environment for the patients and the staffs, since unwanted sound could have a negative impact on patient outcomes and caregiver effectiveness. However, Allaouchiche et al. (2002) found staff conversation caused $56 \%$ of sounds greater than $65 \mathrm{~dB}$ and other noise sources (alarm, telephone, nursing care) were each less than $10 \%$ of these sounds. A review article reported by Ulrich and Zimring (2004) indicated that many studies have shown that noise levels in most hospitals in USA are much higher. They pointed out two general sources of noise in hospitals. The first one includes paging systems, alarms, bedrails, telephones, staff voices, ice machines, pneumatic tubes, carts, and noises generated by roommates. The second source includes the surfaces of the floors, walls, and ceilings which usually are hard and reflect sound rather than absorb it. Blomkvist et al. (2005) studying a coronary critical care unit found that healthcare workers exposed to different levels of noise over the workday reported higher levels of stress and tension. Conversely, the patients judged staff attitudes and care to be much better during the lower acoustical periods. Therefore, it is very important to keep the noise levels down in medical institutions.

The United States Environmental Protection Agency (USEPA) recommended guideline values for continuous background noise are $45 \mathrm{~dB}$ during the day and $35 \mathrm{~dB}$ at night in patient rooms. World Health Organization (WHO) also recommended guideline values for continuous background noise in hospital patient rooms are $35 \mathrm{~dB}$, with nighttime peaks in wards not to exceed $40 \mathrm{~dB}$ ( Berglund et al., 1999 ). According to the Noise Control Act of Taiwan, the background noise limit for a medical institution is $50 \mathrm{~dB}$ at daytime and $40 \mathrm{~dB}$ at nighttime. However, the limit only applies to areas surrounding the institution, rather than inside it. Labor safety and sanitation rules in Taiwan stipulate that the amount of time allowed for exposure to noise measuring $90 \mathrm{~dB}$ is $8 \mathrm{~h}$ daily. It further classifies a working place with noise of above $85 \mathrm{~dB}$ as a hazardous working environment. Soutar and Wilson (1986 ) reported that the average noise levels in the psychiatric, general medical and acute admitting wards are 49, 68 and $66 \mathrm{~dB}(\mathrm{~A})$, respectively. Average noise levels from 07:00 to 23:00 in the general and acute medical wards were almost identical. Bayo et al. ( 1995 ) found most noise equivalent sound levels exceeded $55 \mathrm{~dB}$ (A) in one major hospital in Spain. After a self-answered questionnaire on 295 medical care staffs, the results revealed that the most important noise sources were located primarily inside the hospital. Most workers perceived that noise levels are sufficiently high to interfere with their work and affect patients' comfort and recovery. Buemi et al. (1995) also reported during the day time the maximum sound level at the intensive care unit, hemodialysis room and corridor are $76.8 \mathrm{~dB}$ (A), $67 \mathrm{~dB}$ (A) and $66.8 \mathrm{~dB}$ (A), respectively. Ann et al. (1996 ) measured and evaluated the noise levels in hospital environment and claimed that the average noise value was $60 \mathrm{~dB}(\mathrm{~A})$, which is much higher than those suggested by USEPA ( $45 \mathrm{~dB}$ during the day and $35 \mathrm{~dB}$ at night). The results of their questionnaires also showed that $58 \%$ of patients believed their sleep had been interfered by the noise from staff, equipments and other patients. Morrison et al. (2003) measured the average daytime sound level in a pediatric intensive care unit was $61 \mathrm{~dB}(\mathrm{~A})$, nighttime $59 \mathrm{~dB}(\mathrm{~A})$. Some researchers reported noise levels in the range of $100 \mathrm{~dB}$ to $110 \mathrm{~dB}$ from drills, saws and other equipment in operating room were found and this presents a significant risk for noise-induced hearing loss (Love, 2003; Nott and West, 2003). Kracht et al. (2007) analyzed the noise in the operating rooms of Johns Hopkins hospital and found orthopedic surgery has the highest average equivalent sound level of approximately $66 \mathrm{~dB}$ 
(A). They also found neurosurgery, urology, cardiology and gastrointestinal surgery have the average equivalent sound levels ranging from 62 to 65 $\mathrm{dB}(\mathrm{A})$. However, the peak levels for neurosurgery and orthopedic surgery exceeded $100 \mathrm{~dB}$ over $40 \%$ of the time and the highest peak levels routinely seen during surgery were well in excess of $120 \mathrm{~dB}$. Sobotova et al. (2007) conducted a measurement of noise levels in a hospital environment and concluded that equivalent noise levels $\left(\mathrm{L}_{\mathrm{Aeq}}=71.3 \mathrm{~dB} ; \mathrm{L}_{\text {Aeq,8h }}=68.3 \mathrm{~dB}\right)$ during orthopedic surgery highly exceeded the limits for a hospital environment; the maximal noise levels reached up to $85 \mathrm{~dB}$ (A). In selected hospital wards, equivalent noise levels reached up to $58.7 \mathrm{~dB}(\mathrm{~A})$. Their questionnaire survey results also showed that $64 \%$ of hospital staff members were annoyed by noise at work and $10 \%$ were highly annoyed. Traffic and stationary sources outside the hospital premises and surgical and other equipment inside the hospital, were altogether considered as the main source of noise. Similar results were obtained by Chen et al. (2009) in a series of measurements on noise levels at the lobbies of 11 comprehensive hospitals in central part of Taiwan. They found that noise levels averaged from 60 to 65 $\mathrm{dB}(\mathrm{A})$. A noise level questionnaire was administered as well by the said authors and their results showed that the noise levels derived from the psychological survey correlated well with the cumulative rate of noise. Their findings indicate further that the functioning of the lobby, which is typically designed to have complex functions corresponding to special architectural planning, always results in higher noise in hospitals. These manifest as noise levels, which correlate with the cumulative rate of noise. Therefore, in order to gain better understanding of the sound levels in the different hospital units in Taiwan, as well as to determine how noise affects patients, visitors and the medical care workers, three hospitals were selected in central and southern part of Taiwan. Measurements on sound levels were employed. A self-answered survey questionnaire on the experiences of noise was administered as well.

\section{MATERIALS AND METHODS}

\section{Hospital samples}

One regional hospital (Hospital A) was identified in the central part of Taiwan and two regional hospitals (Hospital B and Hospital C) in the southern part of Taiwan, with 960, 645 and 498 ward beds, respectively.
Medical care personnel (including nurses and administrators), patients and visitors (including patients' family members) were selected randomly and asked to participate in the noise survey.

\section{Measurement of sound levels}

Sound levels were measured using the Lutron sound level meter (Model 4030), with the measuring height fixed at about $1.5 \mathrm{~m}$ above ground surface. This measuring device was calibrated every time before use. Several locations in each hospital were selected for sound level measurements, including nursing stations, ward corridors, ward interiors, registration counters, outpatient waiting area and outpatient hall. Measurements were taken in triplicate (i.e., at time intervals of 0830-0930 h, 1130-1230 $\mathrm{h}$ and 1600-1700 h) on a daily basis. From the triplicate measurements of each time interval, the average was computed. The obtained averaged values were then used for further analysis. Measurement of sound levels were carried on a daily basis, from August 18 to August 22, 2007 in Hospital A; August 11 to August 15, 2007 in Hospital B and July 21 to July 25, 2007 in Hospital C.

\section{Questionnaire survey on noise experience}

A structured questionnaire was prepared to obtain the physiological and psychological reactions and annoyance responses of the medical care staff and the patients and visitors (including inpatients, outpatients, and patients' family members) to the noise pollution in hospitals. The independent variables (demographic characteristics) for both the medical care staff and the patients/visitors included the following: identity (nursing staff, administrator, inpatient, outpatient, and patient's family), sex, age, marital status, religion, and educational background. However, in the questionnaire, four independent variables, namely, hospital department, work shift, work experience, and job title, were applicable only to medical care staff.

The dependent variables for medical care staff included 62 questions and divided into nine sections: (a) the sources of noise (Section 1: two questions involving the noise sources from inside the wards and outside the wards); (b) subjective perception of ambient noise (Section 2: five questions involving distress, inattention, inability to sleep, fright, and dizziness caused by ambient noise); (c) effect of ambient noise on emotion (Section 3: five questions involving communication difficulty, scalp tingling, bad temper, 
irritable mood and increase in pressure); (d) effect of ambient noise on physiology (Section 4: five questions involving tachycardia, tinnitus, headache, susceptibility to fatigue and loss of appetite); (e) experience of noise from different sources inside the wards (Section 5: eleven questions involving sources, such as television sets, opening of drawers or clothes chests, oxygen or suction apparatuses, doors opening or closing, radios beeping, monitor alarms, call bells, phones ringing, patients moaning or crying, medical equipment and talking of visitors or patient's family members); (f) experience of noise from different sources outside the wards (Section 6: seventeen questions involving noise sources, such as printers at nursing stations, call bells at nursing stations, shift exchanges of nursing staff, shouting of nursing staff, rolling of trolley wheels, doors opening or closing, broadcast, renovation of hospitals, talking of visitors or patient's family members, phones ringing, footsteps, children playing, patients moaning or crying, cleaning or sweeping, registration and cashier, television sets and talking of workers at nursing stations); (g) impact of ambient noise on their work performance (Section 7: five questions involving the impact of noise on work efficiency, thinking, degree of obedience, auditory masking, and inattention); (h) attitude toward ambient noise (Section 8: five questions on patients' feelings about noise, considering the sources of noise and reporting to the superintendent or concerned unit, keeping a stable state of mind, considering noise control or persuading to reduce noise volume, and considering ear hearing check regularly) and (i) knowledge of noise pollution improvement (Section 9: seven questions regarding the requirement of adequate maintenance of equipment for noise control and the requirement of explicit and effective management of noise, improving and promoting the noise prevention knowledge of patients, improving and promoting the noise prevention knowledge of visitors and patient's families, improving the noise pollution problems during the daytime, improving noise pollution problems at night and directly advising persons who make noise to minimizeit).

The dependent variables in the questionnaire for patients and visitors included only six sections (total: 45 questions), which were exactly the same as Sections 1 to 6 for medical care staff.

Except for the Section 1, the five-point Likert scale was applied to each question in all of the sections (5- extremely; 4 - very; 3 - sometimes or general; 2 - a little; and $1-$ not at all).

\section{Statistical analysis}

The survey commenced on July 7, 2007 and completed on August 2, 2007. A total of 300 questionnaires for medical care staff (with 100 questionnaires for each hospital) and 300 questionnaires for patients and visitors (with 100, 80, and 120 questionnaires for Hospitals A, B, and C, respectively) were distributed. The valid returned questionnaires were 283 (98, 90 and 95 for Hospitals A, $\mathrm{B}$, and C, respectively) for medical care staff, and 290 (95, 79, 116 for Hospitals A, B and C, respectively) for patients and visitors. The questionnaire passed the validity and reliability tests before distribution. The Cronbach's alpha values of the questionnaire for the medical care staff and for the patients and visitors were 0.861 and 0.978 , respectively. All statistical data analyses were completed using the SPSS 14.0 software.

\section{RESULTS AND DISCUSSION}

Sound levels in hospitals

Table 1 shows the statistical analysis of sound levels measured at different locations in Hospitals A, $\mathrm{B}$, and $\mathrm{C}$. Apparently, the noise was higher in the following locations for all the hospitals: outpatient waiting area, outpatient hall, and registration counter was higher than that at the locations of medical nursing station, medical ward corridor, and medical ward interior. The aforementioned was the general situation, except for the medical nursing station in Hospital A, which had a daily average sound level of $63.0 \mathrm{~dB}$. The sound levels in the medical nursing station, medical ward corridor, and medical ward interior in Hospital A were also higher compared in those in Hospitals B and C. The results from analysis of variance (ANOVA) on the three hospitals showed that the sound levels in the medical nursing station, medical ward corridor, medical ward interior, outpatient waiting area, and registration counter had significant difference $(\mathrm{p}<0.05)$.

The average sound levels measured in these hospitals during daytime were between 52.6 and 64.6 $\mathrm{dB}$, a range similar to those previously reported by other works ( Bayo et al., 1995; Ann et al., 1996; Kracht et al., 2007; Chen et al., 2009 ). However, all of the sound levels measured in the hospitals in the present study were much higher than those suggested by USEPA (i.e., $45 \mathrm{~dB}$ during daytime). Although the Noise 
Int. J. Environ. Sci. Tech., 7 (4), 705-716, Autumn 2010

Table 1: Statistical analysis of sound levels measured at different locations in hospitals A, B and C

\begin{tabular}{|c|c|c|c|c|c|c|c|}
\hline \multirow{2}{*}{ Hospital } & \multirow{2}{*}{$\begin{array}{l}\text { Measuring } \\
\text { Time }\end{array}$} & \multicolumn{6}{|c|}{ Sound levels* } \\
\hline & & Nursing stations & Ward corridors & Ward interiors & $\begin{array}{c}\text { Outpatient } \\
\text { waiting area }\end{array}$ & $\begin{array}{c}\text { Outpatient } \\
\text { hall }\end{array}$ & $\begin{array}{c}\text { registration } \\
\text { counters }\end{array}$ \\
\hline \multirow{4}{*}{ A } & $\begin{array}{l}\text { 08:30-09:30 } \\
\text { Mean(S.E.) }\end{array}$ & $62.5(2.4)$ & $56.5(1.5)$ & $57.3(1.8)$ & $60.5(2.0)$ & 64.7(3.6) & $65.4(2.3)$ \\
\hline & $\begin{array}{l}\text { 11:30-12:30 } \\
\text { Mean(S.E.) }\end{array}$ & $63.0(1.1)$ & $55.9(1.4)$ & 57.6(1.3) & $62.1(2.4)$ & 64.6(0.9) & $64.0(2.5)$ \\
\hline & $\begin{array}{l}\text { 16:00-17:00 } \\
\text { Mean(S.E.) }\end{array}$ & $63.4(0.5)$ & $56.4(2.5)$ & $56.9(1.8)$ & $60.6(2.6)$ & $65.4(3.1)$ & $65.4(2.0)$ \\
\hline & $\begin{array}{l}\text { Daily } \\
\text { Mean(S.E.) }\end{array}$ & $63.0(1.5)$ & $56.2(1.7)$ & 57.3(1.5) & 61.1(2.3) & 64.9(2.6) & $64.9(2.2)$ \\
\hline \multirow{4}{*}{ B } & $\begin{array}{l}\text { 08:30-09:30 } \\
\text { Mean(S.E.) }\end{array}$ & $56.2(6.0)$ & $46.4(1.5)$ & $46.0(5.6)$ & $64.0(2.0)$ & 63.2((3.1) & $65.4(2.6)$ \\
\hline & $\begin{array}{l}\text { 11:30-12:30 } \\
\text { Mean(S.E.) }\end{array}$ & $58.5(3.3)$ & $52.6(1.4)$ & $53.6(3.2)$ & $65.0(1.5)$ & 65.3(3.5) & $66.0(2.2)$ \\
\hline & $\begin{array}{l}\text { 16:00-17:00 } \\
\text { Mean(S.E.) }\end{array}$ & $59.7(2.9)$ & $52.9(1.4)$ & $52.3(2.6)$ & $66.8(2.9)$ & $65.3(2.6)$ & $64.7(0.6)$ \\
\hline & $\begin{array}{l}\text { Daily } \\
\text { Mean(S.E.) }\end{array}$ & $58.1(4.2)$ & $50.6(3.3)$ & $50.6(5.1)$ & $65.3(2.4)$ & $64.6(3.0)$ & 65.4(1.9) \\
\hline \multirow{4}{*}{ C } & $\begin{array}{l}\text { 08:30-09:30 } \\
\text { Mean(S.E.) }\end{array}$ & 53.6(1.5) & $47.3(1.0)$ & 45.1(5.8) & $64.5(2.1)$ & $62.7(2.8)$ & $64.3(0.7)$ \\
\hline & $\begin{array}{l}\text { 11:30-12:30 } \\
\text { Mean(S.E.) }\end{array}$ & $55.8(2.7)$ & $52.0(1.0)$ & $53.8(3.0)$ & $65.8(0.7)$ & $65.2(2.1)$ & $62.5(0.8)$ \\
\hline & $\begin{array}{l}\text { 16:00-17:00 } \\
\text { Mean(S.E.) }\end{array}$ & $57.3(1.2)$ & $53.9(0.9)$ & $52.1(2.0)$ & $66.8(2.1)$ & $64.5(1.7)$ & $62.8(0.4)$ \\
\hline & $\begin{array}{l}\text { Daily } \\
\text { Mean(S.E.) }\end{array}$ & $55.6(2.3)$ & $51.0(3.0)$ & 50.3(5.3) & 65.7(1.9) & 64.1(2.3) & $63.2(1.0)$ \\
\hline \multicolumn{2}{|c|}{ Total daily mean } & $58.9(4.2)$ & $52.6(3.8)$ & $52.7(5.4)$ & $64.0(3.0)$ & $64.6(2.6)$ & $64.5(2.0)$ \\
\hline \multirow{3}{*}{\multicolumn{2}{|c|}{$\begin{array}{l}\text { ANOVA test } \\
\text { among hospitals }\end{array}$}} & \multicolumn{6}{|c|}{$\mathrm{F}$} \\
\hline & & 24.76 & 19.18 & $\begin{array}{l}12.11 \\
\text { Significance }\end{array}$ & 20.03 & 0.33 & 6.38 \\
\hline & & $0.000 *$ & $0.000 *$ & $0.000 *$ & $0.000 *$ & 0.720 & $0.004 *$ \\
\hline
\end{tabular}

Control Act in Taiwan has not yet expressed clearly the required noise limits inside hospitals, the measured noise levels in this study were still higher than the noise limits for first-class noise control areas, such as hospitals (i.e., $50 \mathrm{~dB}$ during the daytime).

\section{Analysis of major noise sources}

Table 2 shows the major noise sources inside and outside the wards of Hospitals A, B and C as perceived by the medical care staff and by the patients and visitors. The surveyed workers in these hospitals conveyed a similar opinion on the major sources of noise (data not shown). According to the data gathered, $51.9 \%$ of nursing staffs mentioned that "talking of visitors or patient's family members" is the major source of noise inside the wards. Meanwhile, $58.3 \%, 58.0 \%, 70.0 \%$ and $83.0 \%$ of them expressed "shouting of nursing staff," "rolling of trolley wheels," “talking of visitors or patient's family members," and "children playing," respectively, are the four major sources of noise outside of the wards.

More than $50 \%$ of surveyed patients and visitors considered "doors opening or closing” and "patients moaning or crying” as the two major noise sources inside the wards. Outside ward premises, they consider "shouting of nursing staff," "doors opening or closing," "renovation of hospitals," "talking of visitors or patients' family members," and "footsteps" as the major sources of noise.

Although these results were not quite similar to those previously observed by Ulrich and Zimring (2004), hospitals in Taiwan should improve their patient visiting programs in order to reduce the noise from "talking of visitors or patient's family members" or “children playing." In addition, publicity materials or warning signs for noise control should be posted in 
Table 2: Major noise sources inside and outside the wards in three hospitals as perceived by medical care staff, patients and visitors

\begin{tabular}{|c|c|c|}
\hline Noise Sources & $\begin{array}{c}\text { Medical Care Staff } \\
\text { Number (percentage) }\end{array}$ & $\begin{array}{l}\text { Patients and Visitors } \\
\text { Number (percentage) }\end{array}$ \\
\hline Inside the wards & $(\mathrm{N}=283)$ & $(\mathrm{N}=290)$ \\
\hline Television sets & $98(34.6 \%)$ & $135(46.6 \%)$ \\
\hline Oxygen or suction apparatuses & $70(24.7 \%)$ & $91(31.4 \%)$ \\
\hline Doors opening or closing & $26(9.2 \%)$ & $175(60.3 \%)$ \\
\hline Radio beeping & $80(28.3 \%)$ & $123(42.4 \%)$ \\
\hline Phone ringing & $55(19.4 \%)$ & $84(29.0 \%)$ \\
\hline Patients moaning or crying & $68(24.0 \%)$ & $154(53.1 \%)$ \\
\hline Medical equipment & $25(8.8 \%)$ & $140(48.3 \%)$ \\
\hline Talking of visitors or patient's family members & $147(51.9 \%)$ & $136(46.9 \%)$ \\
\hline Others & $4(1.4 \%)$ & $126(43.4 \%)$ \\
\hline Shouting of nursing staff & $165(58.3 \%)$ & $147(50.7 \%)$ \\
\hline Rolling of trolley wheels & $164(58.0 \%)$ & $85(29.3 \%)$ \\
\hline Doors opening or closing & $7(2.5 \%)$ & $145(50.0 \%)$ \\
\hline Broadcast & $27(9.5 \%)$ & $128(44.1 \%)$ \\
\hline Renovation of hospitals & $102(36.0 \%)$ & $149(51.4 \%)$ \\
\hline Talking of visitors or patient's family members & $198(70.0 \%)$ & $147(50.7 \%)$ \\
\hline Phone ringing & $105(37.1 \%)$ & $83(28.6 \%)$ \\
\hline Footsteps & $20(7.1 \%)$ & $155(53.4 \%)$ \\
\hline Children playing & $235(83.0 \%)$ & $111(38.3 \%)$ \\
\hline Patients moaning or crying & $68(24.0 \%)$ & $132(45.5 \%)$ \\
\hline Cleaning or sweeping & $23(8.1 \%)$ & $124(42.8 \%)$ \\
\hline
\end{tabular}

prominent locations and even outside hospital wards. Certainly, hospitals should periodically provide nursing staff with educational courses on noise control in order to reduce the noise from "shouting of nursing staff" and "rolling of trolley wheels."

\section{Survey on sound level among nursing staffs}

Student's t-test and ANOVA were used to determine the relationship between each demographic characteristic (independent variable) and each dependent variable. Table 3 shows the results of statistical analyses on the subjective perception of ambient noise, as well as the effects of ambient noise on emotion and physiology. Medical care staff working on graveyard shift or have longer work experiences displayed more sensitivity to noise. Nursing staff with undergraduate degrees appeared less sensitive to noise compared with those with master degrees or belowcollege degrees. Staff members with below-college degrees and nurses working in medical wards claim that ambient noise have more significant effects on their emotions while at work. In addition, medical care staff working on graveyard shift or have more than five years work experience expressed that their emotions at work could be affected seriously by ambient noise. Staff members who were Christians claim that ambient noise has less effect on their physiology while at work. Furthermore, medical care staff with more than five years of work experience deemed that ambient noise has more effect on their physiology at work. Results in Table 4 (only the results showing significant differences are listed) show that most of the staff members with more than five years of work experience expressed that noise from different sources inside the wards was very high. However, staff members between 31 and 40 years old, married, worked the day shift, with more than five-year work experience, or were head nurses considered noise levels from different sources 
Table 3: Statistical analyses on the subjective perception of ambient noise and the effects of ambient noise on emotion and physiology for medical care staff

\begin{tabular}{lcccc}
\hline Parameters & $\mathrm{n}$ & Mean $^{*}$ & S.E. & $\mathrm{p}$ \\
\hline $\begin{array}{l}\text { (1) Subjective perception of ambient noise } \\
\text { Educational background }\end{array}$ & & & \\
$\quad$ below-college degree & 80 & 13.50 & 2.09 & \\
$\quad$ undergraduate degree & 159 & 12.74 & 1.98 & 0.016 \\
$\quad$ master's degree or over & 44 & 13.29 & 1.91 & \\
Work shift & & & & \\
$\quad$ day shift & 164 & 13.12 & 1.93 & \\
$\quad$ night shift & 96 & 12.66 & 1.95 & 0.012 \\
$\quad$ graveyard shift & 23 & 14.00 & 2.61 & \\
Work experience & & & & \\
$\quad$ less than 1 year & 110 & 12.80 & 1.95 & \\
1-3 years & 139 & 12.91 & 2.13 & \\
$\quad$ 3-5 years & 22 & 14.04 & 1.46 & 0.001 \\
more than 5 years & 12 & 14.83 & 0.38 &
\end{tabular}

(2) Effect of ambient noise on emotion

Educational background

below-college degree

undergraduate degree

master's degree or over

Work shift

day shift

night shift

graveyard shift

Work experience

less than 1 year

1-3 years

3-5 years

more than 5 years

Hospital department

medical wards

surgical wards

maternity wards

others

$\begin{array}{lll}80 & 14.37 & 2.35\end{array}$

$\begin{array}{llll}159 & 12.52 & 2.5 & 0.000\end{array}$

$\begin{array}{lll}44 & 13.27 & 2.73\end{array}$

$\begin{array}{lll}164 & 13.23 & 2.57\end{array}$

$\begin{array}{llll}96 & 12.59 & 2.19 & 0.000\end{array}$

$23 \quad 15.08 \quad 3.55$

$\begin{array}{lll}110 & 13.86 & 2.49\end{array}$

$\begin{array}{lll}139 & 12.28 & 2.24\end{array}$

$\begin{array}{lll}22 & 13.04 & 2.91\end{array}$

$12 \quad 17.16 \quad 1.52$

$\begin{array}{lll}82 & 14.45 & 2.81\end{array}$

$\begin{array}{llll}64 & 13.25 & 2.1 & 0.000\end{array}$

$\begin{array}{lll}47 & 11.61 & 2.55\end{array}$

$90 \quad 12.74 \quad 2.23$

(3) Effect of ambient noise on physiology

Religion

no religion

Taoism

Buddhism

Yiguan dao

Christianity

Catholicism

Work experience

less than 1 year

1-3 years

3-5 years

more than 5 years

$\begin{array}{lll}10 & 11.80 & 1.22\end{array}$

$\begin{array}{lll}102 & 11.45 & 2.23\end{array}$

$\begin{array}{lll}77 & 11.63 & 2.57\end{array}$

$\begin{array}{lll}15 & 11.33 & 1.91\end{array}$

$\begin{array}{lll}53 & 10.50 & 2.64\end{array}$

$\begin{array}{lll}26 & 12.26 & 2.16\end{array}$

$\begin{array}{lll}110 & 11.65 & 2.14\end{array}$

$\begin{array}{lll}139 & 11.02 & 2.31\end{array}$

$\begin{array}{llll}22 & 11.72 & 3.31 & 0.019\end{array}$

$\begin{array}{lll}12 & 12.91 & 2.77\end{array}$

* Five-point Likert scale was applied to each question (5 - extremely; 4 very; 3 - sometimes or general; 2 - a little; 1 - not at all).

outside ward premises as very high. Staff members working in surgical wards claim that the noise levels from different sources outside the wards may not be so high. Most medical care workers perceive noise levels outside the wards as much higher compared to inside ward premises.
Table 4: Statistical analyses on the experience of noise from different sources inside the wards and the experience of noise from different sources outside the wards for medical care staff

\begin{tabular}{lcccc}
\hline \multicolumn{1}{c}{ Parameters } & $\mathrm{n}$ & Mean $^{*}$ & S.E. & $\mathrm{p}$ \\
\hline $\begin{array}{l}\text { (1) Experience of noise from different sources inside } \\
\text { the wards }\end{array}$ & & & & \\
Work experience & 110 & 29.78 & 3.06 & \\
$\quad$ less than 1 year & 139 & 30.44 & 3.27 & 0.000 \\
1-3 years & 22 & 28.72 & 2.86 & \\
3-5 years & 12 & 36.33 & 1.30 & \\
more than 5 years &
\end{tabular}

(2) Experience of noise from different sources outside the wards

Age

less than 20 years old $\quad \begin{array}{llll}7 & 46.28 & 2.13\end{array}$

$\begin{array}{llll}21-30 \text { years old } & 205 & 49.90 & 4.41\end{array}$

31-40 years old $\quad 41 \quad 52.31 \quad 7.01$

more than 40 years old $\quad 30 \quad 50.20 \quad 5.56$

Marital status

single

married

others

Work shift

day shift

night shift

graveyard shift

Work experience

less than 1 year

$1-3$ years

3-5 years

$208 \quad 49.62 \quad 4.61$

$62 \quad 52.56 \quad 6.00$

$13 \quad 47.92 \quad 2.69$

$164 \quad 51.03 \quad 5.22$

$\begin{array}{lll}96 & 49.05 & 4.24\end{array}$

$23 \quad 48.95 \quad 5.77$

$110 \quad 48.16 \quad 3.67$

$139 \quad 50.56 \quad 4.69$

$\begin{array}{lll}22 & 51.63 & 4.32\end{array}$

$\begin{array}{llll}\text { more than } 5 \text { years } & 12 & 61.91 & 3.14\end{array}$

Hospital department

medical wards

surgical wards

maternity wards

$\begin{array}{lll}82 & 51.28 & 5.76\end{array}$

$\begin{array}{lll}64 & 48.25 \quad 4.03\end{array}$

$\begin{array}{lll}47 & 51.38 \quad 5.53\end{array}$

$90 \quad 49.96 \quad 4.28$

others

Job title

head nurse

nurse

$\begin{array}{lll}9 & 54.33 & 4.35\end{array}$

nursing assistant

$\begin{array}{lll}180 & 50.20 \quad 5.27\end{array}$

$\begin{array}{lll}8 & 46.87 & 4.96\end{array}$

administrator

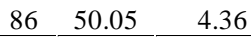

0.006

0.000

0.004

0.000

0.001

* Five-point Likert scale was applied to each question (5 -extremely; 4 very; 3 - sometimes or general; 2 - a little; 1 - not at all).

Results in Table 5 (only the results showing significant differences are listed) show that staff members aged between 31-40 or more than $40 \mathrm{y}$ are more susceptible to the impact of noise on their work performance. Similarly, staff members with belowcollege degrees, deployed in medical and surgical wards and with more than five-year work experience displayed more susceptibility to the impact of noise on their work performance. In contrast, administrators were less sensitive to the effect of noise on their work performance. Medical care staff with at least a master's degree and who have more than five years of work experience showed better attitude towards ambient 
noise. However, both staff working in maternity wards and staff working in graveyard shift expressed aversion towards ambient noise. In addition, staff with at least a master's degree and staff who have more than fiveyear work experience had better knowledge on noise pollution improvement. Correlations for all dependent variables were evaluated (Table 6). Results showed that most of the dependent variables presented significant correlations ( $p<0.05)$, except for the correlations between "subjective perception of ambient noise" and "attitude to ambient noise"; "subjective perception of ambient noise" and "knowledge of noise pollution improvement"; "effects of ambient noise on emotion" and "knowledge of noise pollution improvement" and "effects of ambient noise on physiology" and "knowledge of noise pollution improvement." Findings indicate that noise pollution either directly or indirectly affects, in a simultaneous manner, the subjective perception of noise, emotion, physiology, experience of noise levels inside and outside ward premises, work performance and attitude to ambient noise of the medical care staff.

\section{Survey on sound level among patients and visitors}

Similar to the analysis for medical care staff, results show that patients or visitors who have lower educational attainments displayed more sensitivity to noise (Table 7). Likewise, patients or visitors who are married or who are Taoists or Buddhists appeared more sensitive to noise. Inpatients also displayed stronger reactions on their subjective perception of ambient noise compared with outpatients and visitors. However, both inpatients and outpatients expressed that ambient noise in hospitals has more significant effect on their emotion. Ambient noise in hospitals was also shown to have more significant effects on the emotions of married people and individuals with lower educational levels. Again, patients and visitors who are Buddhists or Christians mentioned that ambient noise has a more significant effect on their emotions. The effects of ambient noise on the emotions of inpatients were also more significant compared with those among outpatients and visitors. Table 8 shows the statistical analyses results of the effects of ambient noise on physiology (only the results showing significant differences are listed). Apparently, ambient noise in hospitals has a more significant effect on the physiology of inpatients and outpatients physiology compared with the visitors. Ambient noise in hospitals also has more
Table 5: Statistical analyses on the impact of ambient noise on their work performance, the attitude toward ambient noise and the knowledge of noise pollution improvement for medical care staffs

\begin{tabular}{|c|c|c|c|c|}
\hline Parameters & No & Mean & S.E. & $\mathrm{p}$ \\
\hline \multicolumn{5}{|c|}{$\begin{array}{l}\text { (1) Impact of ambient noise on their work performance } \\
\text { Age }\end{array}$} \\
\hline less than 20 years old & 110 & 13.28 & 2.13 & \multirow{4}{*}{0.042} \\
\hline 21-30 years old & 139 & 13.88 & 1.94 & \\
\hline $31-40$ years old & 22 & 14.82 & 2.65 & \\
\hline more than 40 years old & 12 & 14.30 & 2.13 & \\
\hline \multicolumn{5}{|l|}{ Educational background } \\
\hline below-college degree & 80 & 14.85 & 1.86 & \multirow{3}{*}{0.000} \\
\hline undergraduate degree & 159 & 13.69 & 2.17 & \\
\hline master's degree or over & 44 & 13.90 & 1.90 & \\
\hline \multicolumn{5}{|l|}{ Hospital department } \\
\hline medical wards & 82 & 14.96 & 2.38 & \multirow{4}{*}{0.000} \\
\hline surgical wards & 64 & 14.26 & 1.44 & \\
\hline maternity wards & 47 & 12.89 & 1.75 & \\
\hline others & 90 & 13.65 & 2.03 & \\
\hline \multicolumn{5}{|l|}{ Work experience } \\
\hline less than $1 \mathrm{y}$ & 110 & 13.92 & 1.55 & \multirow{4}{*}{0.000} \\
\hline $1-3$ years & 139 & 13.69 & 2.21 & \\
\hline 3-5 years & 22 & 14.59 & 1.50 & \\
\hline more than $5 \mathrm{y}$ & 12 & 18.33 & 1.30 & \\
\hline \multicolumn{5}{|l|}{ Job title } \\
\hline head nurse & 9 & 15.33 & 1.00 & \multirow{4}{*}{0.038} \\
\hline nurse & 180 & 14.20 & 2.13 & \\
\hline nursing assistant & 8 & 14.25 & 1.98 & \\
\hline administrator & 86 & 13.59 & 2.06 & \\
\hline
\end{tabular}

(2) Attitude toward ambient noise / Knowledge of noise pollution improvement

Educational background

\begin{tabular}{|c|c|c|c|c|}
\hline below-college degree & 80 & $\begin{array}{c}15.91 / \\
22.75\end{array}$ & $\begin{array}{c}1.27 / \\
2.28\end{array}$ & \multirow{3}{*}{$\begin{array}{l}0.050 \text { / } \\
0.040\end{array}$} \\
\hline undergraduate degree & 159 & $\begin{array}{c}15.41 / \\
22.79\end{array}$ & $\begin{array}{l}1.98 / \\
2.72\end{array}$ & \\
\hline master's degree or over & 44 & $\begin{array}{c}16.02 / \\
24.29\end{array}$ & $\begin{array}{c}2.10 / \\
3.44\end{array}$ & \\
\hline $\begin{array}{l}\text { Hospital department } \\
\text { medical wards }\end{array}$ & 82 & 15.90 / - & 1.17 / - & \multirow{4}{*}{$0.000 /-$} \\
\hline surgical wards & 64 & $16.28 /-$ & 1.59 / - & \\
\hline maternity wards & 47 & $14.65 /-$ & 1.67 / - & \\
\hline others & 90 & $15.48 /-$ & $2.32 /-$ & \\
\hline Work shift & & & & \multirow{4}{*}{$0.019 /-$} \\
\hline day shift & 164 & $15.80 /-$ & $1.96 /-$ & \\
\hline night shift & 96 & 15.62 / - & 1.63 / - & \\
\hline $\begin{array}{l}\text { graveyard shift } \\
\text { Work experience }\end{array}$ & 23 & 14.65 / - & 1.52 / - & \\
\hline less than $1 \mathrm{y}$ & 110 & $\begin{array}{c}15.75 / \\
22.46\end{array}$ & $\begin{array}{c}1.44 / \\
1.93\end{array}$ & \multirow{4}{*}{$\begin{array}{l}0.000 / \\
0.000\end{array}$} \\
\hline $1-3 y$ & 139 & $\begin{array}{c}15.35 / \\
22.91\end{array}$ & $\begin{array}{c}2.15 \text { / } \\
3.14\end{array}$ & \\
\hline $3-5 y$ & 22 & $\begin{array}{c}15.86 / \\
24.09\end{array}$ & $\begin{array}{c}0.83 \text { / } \\
2.04\end{array}$ & \\
\hline more than $5 \mathrm{y}$ & 12 & $\begin{array}{c}17.75 / \\
27.25\end{array}$ & $\begin{array}{c}0.86 \text { / } \\
2.00\end{array}$ & \\
\hline
\end{tabular}

* Five-point Likert scale was applied to each question (5 - extremely; 4 very; 3 - sometimes or general; 2 - a little; 1 - not at all). 
Int. J. Environ. Sci. Tech., 7 (4), 705-716, Autumn 2010

Table 6: Correlation analysis among dependent variables for medical care staffs (sample size $=283$ )

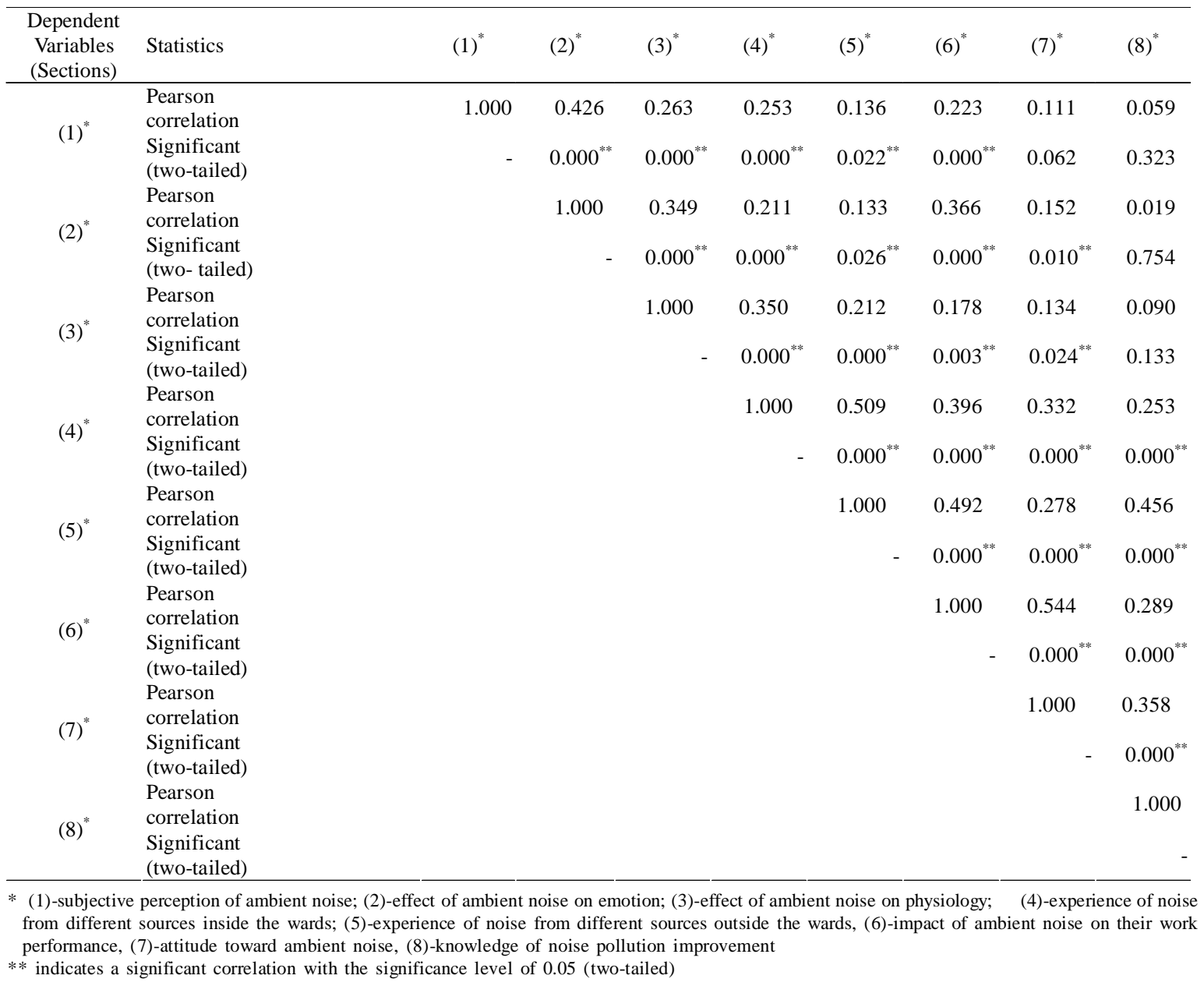

significant effects on the physiology of male patients or male visitors compared with their female counterparts. Results also showed that ambient noise in hospitals has a more significant effect on the physiology of patients and visitors aged 31-50 years or married. Again, ambient noise was expressed to have a more significant effect on patients and visitors who are Buddhists as opposed to those with other religions. The effects of ambient noise on the physiology of inpatients were much higher compared with those of the outpatients and visitors. Table 9 shows the statistical analysis results of the experiences of noise levels from different noise sources inside and outside the wards (only the results showing significant differences are listed). Both inpatients and outpatients experienced higher noise levels from various noise sources inside the wards as opposed to the visitors. Patients and visitors aged 31-50 years, married, and Buddhists or
Christians also experienced higher noise levels from the different noise sources inside ward premises. Similarly, both inpatients and outpatients experienced higher noise levels from different noise sources outside the wards compared with the visitors. Patients and visitors aged 31-50 years, married and Buddhists or Christians also experienced higher noise levels from different noise sources outside ward premises. The correlations of the dependent variables for patients and visitors were also evaluated (Table 10). Results showed that all of the dependent variables presented significant correlations $(p<0.05)$, indicating that noise pollution either directly or indirectly affects, in a simultaneous manner, the subjective perception of noise, emotions, physiology and experience of noise levels inside and outside the wards of the patients and visitors. 
Table 7: Statistical analyses on the subjective perception of ambient noise and effects of ambient noise on emotion for patients and visitors

\begin{tabular}{lcccc}
\hline Variables & $\mathrm{n}$ & Mean $^{*}$ & S.E. & $\mathrm{p}$ \\
\hline $\begin{array}{l}\text { (1) Subjective perception of ambient noise } \\
\text { Educational background }\end{array}$ & & & \\
below high school & 127 & 16.10 & 6.26 & \\
high school to junior college & 103 & 14.42 & 5.80 & 0.006 \\
university and over & 63 & 13.20 & 6.07 & \\
Marital status & & & & \\
single & 82 & 13.06 & 5.81 & \\
married & 186 & 16.13 & 6.06 & 0.000 \\
others & 22 & 11.36 & 5.17 & \\
Religion & & & & \\
no religion & 62 & 13.19 & 5.98 & \\
Taoism & 46 & 16.30 & 5.90 & \\
Buddhism & 87 & 16.56 & 5.90 & \\
Yiguan dao & 23 & 12.70 & 5.46 & 0.001 \\
Christianity & 35 & 15.71 & 5.73 & \\
Catholicism & 29 & 12.62 & 6.80 & \\
others & 8 & 13.13 & 6.45 & \\
& & & & \\
\end{tabular}

(2) Effect of ambient noise on emotion

Identity

\begin{tabular}{lcccc} 
inpatients & 103 & 15.35 & 6.01 & \\
outpatients & 129 & 15.74 & 6.14 & 0.003 \\
patients' family members & 58 & 12.47 & 6.17 & \\
Marital status & & & & \\
single & 82 & 13.59 & 6.21 & \\
married & 186 & 16.24 & 5.87 & 0.000 \\
others & 22 & 9.05 & 4.33 & \\
$\begin{array}{l}\text { Educational background } \\
\text { below high school }\end{array}$ & 127 & 15.82 & 6.53 & \\
high school to junior college & 103 & 14.76 & 5.82 & 0.043 \\
university and over & 63 & 13.42 & 5.89 & \\
Religion & & & & \\
no religion & 62 & 12.97 & 6.88 & \\
Taoism & 46 & 14.80 & 6.05 & \\
Buddhism & 87 & 17.34 & 5.23 & \\
Yiguan dao & 23 & 13.26 & 6.03 & 0.000 \\
Christianity & 35 & 16.00 & 6.08 & \\
Catholicism & 29 & 13.66 & 5.55 & \\
others & 8 & 9.88 & 5.49 & \\
\hline
\end{tabular}

* Five-point Likert scale was applied to each question (5 - extremely; 4 very; 3 - sometimes or general; 2 - a little; 1 - not at all)

\section{CONCLUSION}

In this study, it was found that the average sound levels measured in Hospitals A, B, and C during daytime were between 56.2 and $64.9 \mathrm{~dB}$, between 50.6 and 65.4 $\mathrm{dB}$, and between 50.3 and $65.7 \mathrm{~dB}$, respectively. These values were higher than the environmental daytime noise limit of 50-dB requirement in Taiwan, and certainly surpass the USEPA guideline value of $45 \mathrm{~dB}$ at daytime. The results of this study imply that the hospitals in Taiwan should improve their patient visiting programs in order to minimize noise pollution from major sources, such as "talking of visitors or patient's families” and
Table 8: Statistical analyses on the effects of ambient noise on physiology for patients and visitors

\begin{tabular}{|c|c|c|c|c|}
\hline Variables & $\mathrm{n}$ & Mean $^{*}$ & S.E. & $\mathrm{p}$ \\
\hline \multicolumn{5}{|c|}{$\begin{array}{l}\text { (1) Effect of ambient noise on physiology } \\
\text { Identity }\end{array}$} \\
\hline inpatients & 103 & 15.74 & 6.37 & \multirow{4}{*}{0.000} \\
\hline outpatients & 129 & 15.39 & 5.75 & \\
\hline patients' family member & 58 & 11.31 & 5.90 & \\
\hline \multicolumn{4}{|l|}{ Sex } & \\
\hline nale & 140 & 15.50 & 6.25 & \multirow{2}{*}{0.033} \\
\hline emale & 150 & 13.95 & 6.13 & \\
\hline \multicolumn{5}{|l|}{ Age } \\
\hline less than 30 years old & 64 & 12.25 & 5.63 & \multirow{3}{*}{0.000} \\
\hline 31-50 years old & 163 & 15.99 & 6.08 & \\
\hline more than 51 years old & 63 & 13.83 & 6.36 & \\
\hline \multicolumn{5}{|l|}{ Marital status } \\
\hline single & 82 & 13.23 & 6.22 & \multirow{3}{*}{0.000} \\
\hline married & 186 & 16.05 & 5.92 & \\
\hline others & 22 & 8.73 & 3.58 & \\
\hline \multicolumn{5}{|l|}{ Religion } \\
\hline no religion & 62 & 13.00 & 6.70 & \multirow{7}{*}{0.000} \\
\hline Taoism & 46 & 15.09 & 6.13 & \\
\hline Buddhism & 87 & 17.08 & 4.94 & \\
\hline Yiguan dao & 23 & 12.70 & 5.61 & \\
\hline Christianity & 35 & 14.74 & 6.35 & \\
\hline Catholicism & 29 & 13.90 & 7.04 & \\
\hline others & 8 & 8.13 & 3.31 & \\
\hline
\end{tabular}

* Five-point Likert scale was applied to each question (5 - extremely; 4 very; 3 - sometimes or general; 2 - a little; 1 - not at all).

“children playing.” In addition, publicity materials or warning signs for noise control should be posted in prominent locations, even outside hospital wards. Hospitals should also provide their respective nursing staff workers periodical educational courses on noise control in order to reduce the noise from "shouting of nursing staff” and "rolling of trolley wheels.” As expressed by the medical care staff and by the patients and visitors, significant correlations were found in relation to subjective perception of ambient noise, effect of ambient noise on emotion, effect of ambient noise on physiology, and experience of noise levels from different noise sources inside and outside wards. It can be deduced that noise pollution either directly or indirectly affects, in a simultaneous manner, the subjective perception of noise, emotion, physiology and experience of noise inside and outside the wards of the medical care staff and the patients and visitors.

\section{ACKNOWLEDGEMENTS}

The authors would like to thank the undergraduate students, Yi-Jiun Chen, Jia-Ru Shiau, Shih-Jie Huang, Jung-Chu Lai and Yun-Yu Deng, in the Department of Health Business Administration of Meiho University for helping the sound level measurement and the noise 
Int. J. Environ. Sci. Tech., 7 (4), 705-716, Autumn 2010

Table 9: Statistical analyses on the experience of noise from different noise sources inside the wards and the experience of noise from different noise sources outside the wards for patients and visitors

\begin{tabular}{|c|c|c|c|c|}
\hline Independent variables & $\mathrm{n}$ & Mean $^{*}$ & S.E. & $\mathrm{p}$ \\
\hline \multicolumn{5}{|c|}{$\begin{array}{l}\text { (1)Experience of noise from different sources inside the wards } \\
\text { Identity }\end{array}$} \\
\hline inpatients & 103 & 33.02 & 11.42 & \multirow{3}{*}{0.000} \\
\hline outpatients & 129 & 33.12 & 10.78 & \\
\hline patients' family members & 58 & 25.69 & 12.08 & \\
\hline \multicolumn{5}{|l|}{ Sex } \\
\hline male & 140 & 32.99 & 11.41 & \multirow{2}{*}{0.048} \\
\hline female & 150 & 30.29 & 11.70 & \\
\hline \multicolumn{5}{|l|}{ Age } \\
\hline less than 30 years old & 64 & 28.70 & 11.14 & \multirow{3}{*}{0.002} \\
\hline $31-50$ years old & 163 & 33.66 & 11.30 & \\
\hline more than 51 years old & 63 & 29.19 & 12.01 & \\
\hline \multicolumn{5}{|l|}{ Marital status } \\
\hline single & 82 & 29.74 & 12.17 & \multirow{3}{*}{0.000} \\
\hline married & 186 & 33.91 & 10.85 & \\
\hline others & 22 & 18.91 & 4.55 & \\
\hline \multicolumn{5}{|l|}{ Religious belief } \\
\hline $\begin{array}{l}\text { no religious belief } \\
\text { Taoism }\end{array}$ & $\begin{array}{l}62 \\
46\end{array}$ & $\begin{array}{l}28.16 \\
3139\end{array}$ & $\begin{array}{l}13.06 \\
10.79\end{array}$ & \multirow{6}{*}{0.000} \\
\hline Buddhism & 87 & 36.24 & 9.39 & \\
\hline Yiguan dao & 23 & 25.96 & 10.59 & \\
\hline Christianity & 35 & 34.20 & 11.17 & \\
\hline Catholicism & 29 & 29.86 & 12.05 & \\
\hline others & 8 & 20.00 & 6.23 & \\
\hline
\end{tabular}

(2)Experience of noise from different sources outside the wards Identity

\begin{tabular}{lccrl} 
inpatients & 103 & 51.94 & 15.38 & \\
outpatients & 129 & 52.66 & 14.65 & 0.001 \\
patients' family members & 58 & 44.07 & 15.25 & \\
$\begin{array}{l}\text { Age } \\
\text { less than 30 years old }\end{array}$ & 64 & 46.39 & 13.12 & \\
$\begin{array}{l}\text { 31-50 years old } \\
\text { more than 51 years old }\end{array}$ & 163 & 53.45 & 15.33 & 0.002 \\
$\begin{array}{l}\text { Marital status } \\
\text { single }\end{array}$ & 63 & 47.90 & 16.20 & \\
married & 82 & 46.82 & 15.900 & \\
others & 186 & 53.90 & 14.71 & 0.000 \\
Religious belief & 22 & 37.91 & 6.31 & \\
no religious belief & & & & \\
Taoism & 62 & 46.79 & 17.08 & \\
Buddhism & 46 & 51.24 & 14.96 & \\
Yiguan dao & 87 & 55.45 & 13.55 & \\
Christianity & 23 & 45.65 & 16.01 & 0.002 \\
Catholicism & 35 & 53.20 & 14.35 & \\
others & 29 & 47.79 & 15.43 & \\
\hline
\end{tabular}

* Five-point Likert scale was applied to each question (5 - extremely; 4 very; 3 - sometimes or general; 2 - a little; 1 - not at all)

questionnaire survey in this study for helping the sound level measurement and the noise questionnaire survey in this study.

\section{REFERENCES}

Allaouchiche, B.; Duflo, F.; Debon, R.; Bergeret, A.; Chassard, D., (2002). Noise in the postanaesthesia care unit. Br. J.
Table 10: Correlation analysis among dependent variables for patients and visitors (sample size $=290$ )

\begin{tabular}{|c|c|c|c|c|c|c|}
\hline $\begin{array}{c}\text { Dependent } \\
\text { Variables } \\
\text { (Sections) } \\
\end{array}$ & Statistics & $(1)^{*}$ & $(2)^{*}$ & $(3)^{*}$ & $(4)^{*}$ & $(5)^{*}$ \\
\hline \multirow{2}{*}{$(1)^{*}$} & $\begin{array}{l}\text { Pearson } \\
\text { correlation }\end{array}$ & 1.000 & 0.720 & 0.751 & 0.666 & 0.591 \\
\hline & $\begin{array}{l}\text { Significant } \\
\text { (two-tailed) }\end{array}$ & - & $0.000^{* *}$ & $0.000^{* *}$ & $0.000^{* *}$ & $0.000^{* *}$ \\
\hline \multirow{2}{*}{$(2)^{*}$} & $\begin{array}{l}\text { Pearson } \\
\text { correlation }\end{array}$ & & 1.000 & 0.776 & 0.770 & 0.660 \\
\hline & $\begin{array}{l}\text { Significant } \\
\text { (two-tailed) }\end{array}$ & & - & $0.000^{* *}$ & $0.000^{* *}$ & $0.000^{* *}$ \\
\hline \multirow{2}{*}{$(3)^{*}$} & $\begin{array}{l}\text { Pearson } \\
\text { correlation }\end{array}$ & & & 1.000 & 0.847 & 0.776 \\
\hline & $\begin{array}{l}\text { Significant } \\
\text { (two-tailed) }\end{array}$ & & & - & $0.000^{* *}$ & $0.000^{* *}$ \\
\hline \multirow{2}{*}{$(4)^{*}$} & $\begin{array}{l}\text { Pearson } \\
\text { correlation }\end{array}$ & & & & 1.000 & 0.855 \\
\hline & $\begin{array}{l}\text { Significant } \\
\text { (two-tailed) }\end{array}$ & & & & - & $0.000^{* *}$ \\
\hline \multirow{2}{*}{$(5)^{*}$} & $\begin{array}{l}\text { Pearson } \\
\text { correlation }\end{array}$ & & & & & 1.000 \\
\hline & $\begin{array}{l}\text { Significant } \\
\text { (two-tailed) }\end{array}$ & & & & & - \\
\hline
\end{tabular}

* (1)-subjective perception of ambient noise; (2)-effect of ambient noise on emotion; (3)-effect of ambient noise on physiology; (4)-experience of noise from different sources inside the wards; (5)-experience of noise from different sources outside the wards. ${ }^{* *}$ indicates a significant correlation with the significance level of 0.05 (two-tailed).

Anaesth., 88 (3), 369-373 (5 pages).

Ann, L.; Helen, M., Jeanette, M., (1996). Noise in the hospital: A quality improvement approach. J. of Nurs. Administ., 26, 3-4 (2 pages).

Banerjee, D., (2008). Study of precipitation chemistry over an industrial city. Int. J. Environ. Sci. Tech., 5 (3), 331338 (8 pages).

Banerjee, D.; Chakraborty, S. K.; Bhattacharyya, S.; Gangopadhyay, A., (2009). Attitudinal response towards road traffic noise in the industrial town of Asansol. Environ. Monit. Assess., 151(1-4), 37-44 (8 pages).

Bayo, M. V.; García, A. M.; García A., (1995). Noise levels in an urban hospital and workers' subjective responses. Arch. Environ. Health, 50 (3), 247-251 (5 pages).

Berglund, B.; Lindvall, T.; Schwela, D. H., (1999). Guidelines for community noise. World Health Organization, Geneva.

Blomkvist, V.; Cole, J.; Ulrich, R. S., (2005). Impact of acoustics on staff and patients in CCU. Hosp/ Develop., 36 (10), 1922 (4 pages).

Buemi, M.; Allegra, A.; Grasso, F.; Mondio, G., (1995). Noise pollution in an intensive care unit for nephrology and dialysis. Nephrol. Dial. Transplant., 10 (12), 2235-2239 (5 pages).

Chen, C. Y., Hung, K. F., Chen, J. L., (2009). Investigation of the Relationship between Noise Controls and Human Behaviours in the General Hospital Buildings of the Central Taiwan. J. Temporal. Des. Arch. Environ., 9 (1), 34-37 (4 pages).

Cmiel, C. A.; Karr, D. M.; Gasser, D. M.; Oliphant, L. M.; 
Neveau, A. J., (2004). Noise control: A nursing team's approach to sleep promotion. Am. J. Nurs., 104 (2), 40-48 (9 pages). Freedman, N. S.; Gazendam, J.; Levan, L.; Pack, A. I.; Schwab, R. J., (2001). Abnormal sleep/wake cycles and the effect of environmental noise on sleep disruption in the intensive care unit. Am. J. Respir. Crit. Care Med., 163 (2), 451-457(7 pages).

Freedman, N. S.; Kotzer, N.; Schwab, R. J., (1999). Patient perception of sleep quality and etiology of sleep disruption in the intensive care unit. Am. J. Respir. Crit. Care Med., 159 (4), 1155-1162 (8 pages).

Giardino, D. A.; Durkt, G. Jr., (1996). Evaluation of muff-type hearing protectors as in a working environment. Am. Ind. Hyg. Assoc. J., 57 (3), 264-271 (8 pages).

Holmberg, S.; Coon, S., (1999). Ambient sound levels in state psychiatric hospital. Arch. Psychiatr. Nurs., 13 (3), 117-126 (10 pages).

Ising, H.; Kruppa, B., (2004). Health effects caused by noise: Evidence in the literature from the past 25 years. Noise Health, 6 (22), 5-13 (9 pages).

Job, R. F. S., (1996). The influence of subjective reactions to noise on health effects of the noise. Environ. Int., 22 (1), 93-104 (12 pages).

Keipert, J. A., (2008). The harmful effects of noise in a children's ward. J. Paediatr. Child Health, 21 (2), 101-103 (3 pages).

Kracht, J. M.; Busch-Vishniac, I. J.; West, J. E., (2007). Noise in the operating rooms of Johns Hopkins hospital. J. Acoust. Soc. Am, 121 (5), 2673-2680 (8 pages).

Love, H. (2003). Noise exposure in the orthopaedic operating theatre: A significant health hazard. ANZ J.Surg., 73 (10), 836-838 (3 pages).

Meyer-Falcke, A., Rack, R., Eichwede, F., Jansing, P. J., (1994). How noisy are anaesthesia and intensive care medicine? Quantification of the patients' stress. Eur. J. Anaesthesiol., 11 (5), 407-411 (5 pages).

Monazzam, M. R.; Nassiri, P., (2009). Performance of profiled vertical reflective parallel noise barriers with quadratic residue diffusers. Int. J. Environ. Res., 3 (1), 69-84 (16 pages).

Morrison, W. E.; Haas, E. C.; Shaffer, D. H.; Garett, E. S.; Fackler, J. C., (2003). Noise, stress, and annoyance in a pediatric intensive care unit. Crit. Care Med., 31 (1), 113119 (7 pages).

Nassiri, P.; Golbabai, F., (1993). The effect of noise induced hearing loss on dentists. Med. J. Iran., 7 (2), 83-86 (4 pages). Nicholas, A.; Bach, V.; Tassi, P.; Dewasmes, G.; Erhart, J.; Muzet, A.; Lipert, J. P., (1993). Electroencephalogram and cardiovascular responses to noise during daytime sleep in shift workers. Eur. J. Appl. Physiol. Occup. Physiol., 66(1), 76-84 (9 pages).

Nott, M. R.; West, P. D., (2003). Orthopaedic theatre noise: A potential hazard to patients. Anaesthesia, 58(8), 784-787 (4 pages).

Omidvari, M.; Nouri, J., (2009). Effects of noise pollution on traffic policemen. Int. J. Environ. Res., 3 (4), 645-652 (8 pages).

Penney, P. J.; Earl, C. E., (2004). Occupational noise and effects on blood pressure: exploring the relationship of hypertension and noise exposure in workers. Am. Assoc. Occup. Health Nurses J., 52(11), 476-480 (5 pages).

Piccolo, A.; Plutino, G.; Cannistraro, G., (2005). Evaluation and analysis of the environmental noise of Messina, Italy. Appl. Acoust., 66 (4), 447-465 (19 pages).

Roozbahani, M. M.; Nassiri, P.; Shalkouhi, P.J., (2009). Risk assessment of workers exposed to noise pollution in a textile plant. Int. J. Environ. Sci. Tech., 6 (4), 591-596 (6 pages).

Selfe, R. W., (1982). The ear and hearing: ear, nose and throat in the workplace. In: Clinical Medicine for the Occupational Physician. Alderman, M. H. and Hanley, M. J., eds., Marcel Dekker, New York: 507-522.

Sobotova, L.; Jurkovicova, J.; Stefanikova, Z.; Sevcikova, L.; Aghova, L., (2007). Noise levels in the hospital environment and health risks. Epidemiology, 18 (5), S73.

Soutar, R. L.; Wilson, J.A., (1986). Does hospital noise disturb patientsÿ Br. Med. J., 6516, 292-305 (14 pages).

Tang, U. W.; Wang, Z. S., (2007). Influences of urban forms on traffic-induced noise and air pollution: Results from a modeling system. Environ. Model. Softw., 22 (12), 1750-1764 (15 pages).

Ulrich, R.; Zimring, C., (2004). The role of the physical environment in the hospital of the 21st Century: a once-ina-lifetime opportunity. The Center for Health Design, California, USA.

Van Kempen, E. E. M. M.; Kruize, H.; Boshuizen, H. C.; Ameling, C. B.; Staatsen, B. A. M.; de Hollander, A. E. M., (2002). The association between noise exposure and blood pressure and ischemic heart disease: A meta-analysis. Environ. Health Perspect., 110 (3), 307-317 (11 pages).

Willett, K. M., (1991). Noise-induced hearing loss in orthopaedic staff. J. Bone Joint Surg., 73-B(1), 113-115 (3 pages).

Yildirim, I.; Kilinc, M.; Okur, E.; Inanc Tolun, F.; Kilic, M. A.; Kurutas, E. B.; Ekerbicer, H.C., (2007). The effects of noise on hearing and oxidative stress in textile workers. Ind. Health, 45 (6), 743-749 (7 pages).

\footnotetext{
AUTHOR (S) BIOSKETCHES

Juang, D. F., Ph.D., Associate Professor, Department of Health Business Administration, Meiho University, 24F, 230, Ming-Chuan Second Road, Kaohsiung 806, Taiwan. Email: x00002060@email.meiho.edu.tw

Lee, C. H., Ph.D., Assistant Professor, Department of Health Business Administration, Meiho University, 23, Ping Kuang Road, Neipu, Pingtung County 912, Taiwan. Email: x00002167@meiho.edu.tw

Yang, T., Ph.D., Assistant Professor, Department of Health Business Administration, Meiho University, 23, Ping Kuang Road, Neipu, Pingtung County 912, Taiwan. Email: x00002115@meiho.edu.tw

Chang, M. C., M. D., Director, Longcyuan Veterans Hospital, Neipu, Pingtung County 912, Taiwan. Email: smartzhang0205@gmail.com
}

How to cite this article: (Harvard style)

Juang, D. F.; Lee, C. H.; Yang, T.; Chang, M. C., (2010). Noise pollution and its effects on medical care workers and patients in hospitals. Int. J. Environ. Sci. Tech., 7 (4), 705-716. 